\title{
SENTIDOS E IMPLICAÇÕES DO PROCESSO DE JUDICIALIZAÇÃO DA POLÍTICA NO BRASIL
}

\author{
SENTIDOS E IMPLICACIONES DEL PROCEDIMIENTO DE \\ JUDICIALIZACIÓN DE LA POLÍTICA EN BRASIL
}

\author{
SIGNS AND IMPLICATIONS OF THE POLICY JUDICIALIZATION PROCESS \\ IN BRAZIL
}

João Pedro MACIEL ${ }^{1}$

RESUMO: Debate recente e profícuo na Ciência Política, o fenômeno da judicialização da política constitui-se de uma nova dinâmica imanente aos sistemas democráticos modernos e as sociedades pautadas pela ideia de aquisição de direitos. Buscando compreender esse tema, o presente artigo busca apresentar o estado de arte desses estudos nas Ciências Humanas, assim como descrever os principais conceitos que orientam essa discussão.

PALAVRAS-CHAVE: Judicialização. Democracia. Direitos.

RESUMEN: Debate reciente y provechoso en la Ciencia Política, el fenómeno de la judicialización de la política se constituye de una nueva dinámica inmanente a los sistemas democráticos modernos y las sociedades pautadas por la idea de adquisición de derechos. En busca de este tema, el presente artículo busca presentar el estado de arte de esos estudios en las Ciencias Humanas, así como describir los principales conceptos que orientan esa discusión.

PALABRAS CLAVE: Legalización. Democracia. Derechos.

ABSTRACT: A recent and fruitful debate in Political Science, the phenomenon of the judicialization of politics is a new dynamic immanent to modern democratic systems and societies guided by the idea of rights. Seeking to understand this theme, this article seeks to present the state of art of these studies in the Human Sciences, as well as to describe the main concepts that guide this discussion.

KEYWORDS: Judicialization. Democracy. Rights.

\section{Introdução}

${ }^{1}$ Universidade Estadual Paulista (Unep), Faculdade de Ciências e Letras, Araraquara - SP - Brasil. Graduando em Ciências Sociais. E-mail: maciel.jpedro@gmail.com. 
A grande transformação ocorrida no funcionamento do sistema capitalista nas últimas décadas - com o predomínio do mercado financeiro sobre a produção industrial - resultaram no realinhamento do sistema internacional de poderes, conflagrando um processo de perda de autonomia do Estado-nação diante dos interesses do capital financeiro internacional. Diante da redução da capacidade estatal em promover respostas satisfatórias às demandas societárias, alteraram-se de maneira substancial os processos de formulação e consolidação de políticas públicas, no modo de legitimá-las e nas relações entre os poderes que compõem as nações republicanas.

Diante da insuficiência do poder público na concretização dos preceitos fundamentais que legitimam as democracias contemporâneas, atribui-se ao poder judiciário papel fundamental e protagonismo político na defesa dos interesses das sociedades modernas, pautadas na ideia da aquisição de direitos. Com o aprofundamento de sucessivas crises econômicas e retração do poder estatal, a mobilização das massas em torno das reivindicações de suas demandas tornam-se cada vez mais presentes. As novas dinâmicas nas relações entre sociedade e Estado acirram o processo de instrumentalização das instituições jurídicas enquanto promotoras e defensoras de princípios e preceitos constitucionais, fortalecendo sua participação no jogo político-partidário e ideológico.

A utilização de recursos jurídicos enquanto ferramentas para normatização do comportamento e sociabilidade tornaram-se preceitos fundamentais na consolidação do mundo moderno, tornado o processo de judicialização da vida ordinária um processo inerente as sociedades contemporâneas. No Brasil, o processo surge com a redemocratização do país a partir da promulgação da Constituição Federal de 1988, ao expandir e fortalecer o poder judiciário enquanto guardião constitucional e aplicador das leis.

A partir da consubstanciação de suas prerrogativas clássicas, o poder Judiciário expandiu seu campo de atuação para dimensões tradicionalmente atribuídas ao Poder Executivo e Legislativo. Diante da ineficácia desses poderes na canalização dos interesses dos grupos sociais organizados, a população passou a buscar a proteção de seus interesses perante juízes, procuradores e tribunais judiciários. A adoção de um tribunal supremo como mecanismo mediador da constitucionalidade da atuação dos demais poderes implica em alterações para a implantação de políticas públicas. Esse mecanismo não só viabilizou a participação do Judiciário nos processos decisórios como também o colocou em uma situação estratégica diante dos outros poderes.

Diversas pesquisas foram desenvolvidas com o objetivo de entender o funcionamento das instituições judiciais e as suas relações com os demais poderes no Brasil. Algumas 
definições sugerem a pré-existência do ativismo judicial, que implica extensão do poder judiciário na interpretação da legislação. O mediador pode atuar politicamente de acordo com as suas próprias subjetividades, colocando os seus projetos políticos acima da igualdade jurídica.

Buscando lançar luzes sobre o debate e propor uma reflexão sobre a relevância do assunto para o entendimento do atual momento histórico, o presente trabalho procurou traçar um breve panorama a respeito do estado de arte da temática nos círculos acadêmicos, e a partir dai estabelecer as relações com a atuação constitucional e política das instituições jurídicas nacionais.

Para tanto, o trabalho se divide em três seções: na primeira são apresentadas as principais contribuições teóricas a respeito do fenômeno da judicialização da atividade política, a fim de esclarecer o conceito e suas consequências. $\mathrm{Na}$ segunda parte foram apresentadas as principais diferenças teóricas entre o processo de judicialização e ativismo jurídico, com o propósito de compreender suas implicações para a luta política e o processo democrático. Por último, buscou-se problematizar os temas anteriormente discutidos na análise do caso brasileiro, a luz da conformação do sistema jurídico nacional e seus desdobramentos na regulação da atuação dos demais poderes.

Em relação à última seção, o presente trabalho limitou-se a explicitar as principais diretrizes e sentidos pelo qual o fenômeno se apresenta no Brasil, assim como elencar brevemente as principais ferramentas que possibilitam a interferência do sistema judicial no jogo político tradicional. Apesar da acentuada influência que o processo analisado influiu sobre os grandes acontecimentos recentes, como no impeachment da ex-presidente Dilma Rousseff, a complexidade dos acontecimentos aliados a imprevisibilidade do cenário político impossibilitam uma análise mais acurada e precisa dos fatos, justificando assim a escolha do autor em se deter a discussão teórica sobre a estruturação do fenômeno no Brasil.

\section{Conceitos e pressupostos da judicialização da política}

No campo das Ciências Humanas, a expansão das atividades dos poderes judiciais em matérias cujas atividades são inerentes ao demais poderes da república são compreendidas enquanto tendências mundiais nas democracias modernas. É a partir desta constatação que o fenômeno torna-se objeto de estudo da Ciência Política, cujos marcos iniciais deste novo campo conceitual toma como referência a obra The global expansion of judicial power de Tate e Vallinder (1994), criadora do termo "judicialização da política". A partir dessa 
publicação diversas pesquisas foram desenvolvidas, tanto no Brasil como no exterior, a fim de aprimorar o conhecimento do funcionamento das instituições judiciais e as suas relações com os demais poderes no Brasil.

Outros estudos importantes realizados na área também foram realizados por Habermas (2003), Cappelleti (1992; 1993) e Maus (2000), dentre outros. No Brasil, os estudos de maior relevância foram realizados por pesquisadores como Maciel (2002), Vianna (2005), Koerner (2002) e Carvalho (2004), dentre diversos outros que se debruçaram sobre as complexas interlocuções entre os poderes no Estado brasileiro. De acordo com a conceituação do termo realizada pelos autores citados, a judicialização da política pode ser entendida a partir da:

[...] utilização por parte dos poderes políticos de procedimentos tipicamente judiciais para a solução de seus conflitos, ou seja, configuraria o empenho do legislativo e do executivo em adotar procedimentos idênticos aos judiciais. (NAPOLITANO, 2008, p. 19).

Ao relacionar a dimensão da práxis política com a atuação de grupos de pressões sob os membros magistrados das supremas cortes, a definição conceitual proposta pelos pesquisadores pressupõe a orientação ideológica no regime processual utilizados pelos juízes, em detrimento da orientação estrita aos regimentos que regulamentam e orientam as dinâmicas nas casas legislativa em consonância com os ditames constitucionais. A definição impõe então a preexistência de um comportamento politicamente orientado dos agentes que compõem as instâncias superiores dessas instituições, conformado o que se convencionou chamar na bibliografia especializada de ativismo jurídico. Este modo de guiar a conduta dos agentes judiciais é parte integrante do processo de judicialização da política, porém com diferenças substâncias que serão abordadas posteriormente neste trabalho.

Invertendo-se a chave nas relações dos agentes que compõem os poderes da União, o termo também pode ser compreendido como a possibilidade de revisão, na instância jurídica, de decisões tomadas pelos demais poderes tendo como eixo basilar o desenho constitucional das instituições políticas brasileiras. Sua operacionalidade se realiza através do processo de controle de constitucionalidade das leis (CARVALHO, 2004), possibilitando ao judiciário a capacidade de intervir e influenciar nos processos decisórios dos poderes executivos e legislativos.

Vallinder, teórico que cunhou a expressão, entende a judicialização da política como a expansão da jurisdição das cortes ou dos juízes sob as pretensões e modus operandi tradicionais à prática política ou, em outras palavras, a transferência da esfera decisória das instituições essencialmente políticas para as cortes de justiça (NAPOLITANO, 2008, p. 19- 
20). Destaca-se na definição de Vallinder a mesma base argumentativa daquela apresentada por Koerner, Maciel, Oliveira, V. e Teixeira: a judicialização é definida a partir do pressuposto da utilização de métodos e procedimentos tipicamente políticos na atuação dos magistrados. Consequentemente, estes deixam de orientar suas ações através dos códigos prescritivos da liturgia jurídica, pautando-se através de suas acepções e interesses ideológicos individuais.

[...] a expansão das atribuições do poder judiciário, que lhe possibilita a participar das decisões políticas, função classicamente atribuída ao legislativo e executivo; a utilização de mecanismos tipicamente judiciais para solucionar conflitos na arena política; e a adoção pelo judiciário de procedimentos característicos dos poderes políticos para a solução de problemas jurídicos, como, por exemplo, a utilização de atitudes, valores e preferências pessoais dos juízes no momento da tomada de decisões. (NAPOLITANO, 2008, p. 21).

$\mathrm{Na}$ acepção adotada pelo autor, o processo de judicialização é fundamentado no processamento jurídico de conflitos e decisões tradicionalmente atribuídas aos demais poderes componentes do estado, possibilitado através do desenho institucional e normativo que expande os poderes das instâncias jurídicas. Em outras palavras, a judicialização representa o processo de inter-relação e assimetria entre os poderes, favorecidas pela supraestrutura jurídico-constitucional que normatiza e dimensiona o estamento burocrático nacional.

Enquanto representação de determinado arranjo constitucional, o processo de judicialização pressupõe determinadas peculiaridades dos regimes políticos contemporâneos. O primeiro reside na existência do regime democrático, dado que diferentes conformações políticas impossibilitariam maior autonomia e expansão da esfera jurídica; o segundo aspecto refere-se à existência do equilíbrio de poderes preconizados pela teoria montesquiana, onde exista a garantia da permissão para os juízes interpretarem e aplicarem as leis. Por último, a existência de uma carta de direitos e garantias aos cidadãos, fundamentadas em um texto constitucional, torna-se elemento basilar em garantir aos indivíduos e grupos de pressões impetrarem recursos ao judiciário a fim de defender seus interesses, sobretudo em relação aos grupos minoritários no enfrentamento das decisões de maiorias eventuais (TATE, 1994).

Em consequência da ampliação das atividades do judiciário, passou-se também a questionar se a intervenção judicial nas decisões é ou não benéfica para a experiência democrática. Considerando que, historicamente, as decisões políticas sempre foram incumbência do executivo e legislativo, cujos agentes políticos são democraticamente eleitos 
através do voto direto, em detrimento da não participação popular nos processos que ordenam a composição das supremas cortes jurídicas.

\section{Judicialização, ativismo jurídico e democracia}

O processo de judicialização é fundamentando no ordenamento jurídico e institucional de uma nação democrática, não refletindo diretamente as orientações políticas e partidárias dos magistrados. Por outro lado, o ativismo judicial remete aos comportamentos dos árbitros em relação às suas escolhas orientadas de acordo com seus interesses próprios ou de seus aliados. O ativismo implica na extensão do poder discricionário do juiz na interpretação da legislação, ocasionando assim na extensão do sentido e do alcance da interpretação dos preceitos constitucionais (FREITAS, 2011).

Especificamente no caso brasileiro, a judicialização ocorre, por sua vez, a partir dos traços formativos de um modelo constitucional analítico, operado através do sistema de controle direto de constitucionalidade. O processo que dai resulta permite o processamento de matérias políticas a partir de ações judiciais, em decorrência das diretrizes formuladas na Constituição, em detrimento das pretensões e interesses da classe dirigente do sistema Judiciário.

Buscando traçar um panorama abrangente a respeito das diferenças conceituais entre o processo de judicialização e o ativismo judicial, a formulação teórica desenvolvida por Barroso (2008) aponta o ativismo como uma participação mais intensa dos órgãos judiciários na efetivação de valores e fins constitucionais, através de uma maior interferência no campo de atuação dos outros poderes. O ativismo torna-se, assim, visível por meio das posturas adotadas pelos árbitros das supremas cortes, o que inclui:

(1) o uso das prescrições da Constituição a outras matérias não contempladas pela Lei magna, de forma direta, mesmo que exista legislação ordinária referente; (2) relativização e afrouxamento dos critérios para declaração de inconstitucionalidade a produções de legisladores ordinários; (3) intervenção na conduta do Poder Público, em matéria de execução de políticas públicas, entre outras. Em síntese, o ativismo judicial se empenha em aplicar as garantias constitucionais de forma mais ampla e inclusiva possível, sem, entretanto, adentrar e dominar o processo de criação livre do Direito. Configura-se como um mecanismo para driblar a morosidade, inércia ou ineficácia do processo político majoritário e da produção de consenso. (FREITAS, 2011 apud BARROSO, 2008. p. 40).

Na conceituação de Alexandre Garrido Silva e Vieira (1996), a distinção entre a prática de ativismo e judicialização encontra-se na inclinação dos agentes judiciais em revisar 
as pautas e discussões no âmbito dos outros poderes, enquanto o fenômeno da judicialização se caracteriza por sua natureza ampla e estruturada em preceitos legais, abrangendo sistematicamente condições institucionais e políticas que fomentam alterações no centro decisório das diretrizes estritamente políticas para a esfera do judiciário.

Outra contribuição de suma importância para os estudos acerca da judicialização foi apresentada por Marshall (2002). Em suas reflexões a respeito do tema, o autor tipifica sete formas de ativismo judicial. De acordo com sua tese, este fenômeno é representado por:

(1) ativismo contra majoritário, no qual há resistência quanto à validade das decisões dos outros poderes; (2) ativismo não originalista, que não inova ao interpretar as regras jurídicas, sem análises abrangentes e amplas do texto constitucional, bem como das intenções de sua formulação; (3) ativismo de precedentes, que rejeita os precedentes já estabelecidos; (4) ativismo formal (jurisdicional), que contesta os limites legais estabelecidos para a atuação das Cortes; (5) ativismo material (ou criativo), que resulta da criação de novos direitos ou teorias no âmbito da doutrina constitucional; (6) ativismo remediador, marcado pela atuação impositiva do Judiciário em questão de delegar atribuições e funções aos outros Poderes ou controlar ou corrigir tais ações por meio de imposições jurídicas; e, por fim, (7) ativismo partiram, em que o poder judicial é utilizado por partidos ou segmentos sociais para atendimento de demandas específicas. (FREITAS, 2011 apud MARSHALL, 2002).

Na formulação adotada por Marshall (2002), pode-se constatar o caráter dinâmico e multifacetado pelos quais pode atuar o magistrado em sua militância jurídica, apresentado aspectos que podem resultar e influenciar diretamente em uma ampla variedade de ações, tanto no sentido da expansão e fortalecimento da experiência democrática da sociedade civil, ou no sentido inverso, ao sobrepor interesses privados diante da dimensão coletiva da sociedade, a partir de uma postura de tendências conservadoras bastante presentes nas instâncias jurídicas superiores.

O ativismo judicial pode ser mensurado a partir das regularidades com que os agentes judiciais invalidam as ações e deliberações das outras esferas, sobretudo do Legislativo. Em torno dos debates conceituais a respeito do tema, não há consenso sobre se a judicialização estabelece desequilíbrio ou reequilíbrio entre as três esferas de poder do Estado, mas não há objeções quanto ao fato de o Poder Judicial ter se tornado fonte institucional do debate público. (MELLO, 2009).

Outro elemento a se destacar é que o fenômeno da militância política nas supremas cortes pode ocorrer em sentido contrário. A autocontenção judicial é representada pelo movimento no qual o judiciário reduz sua participação e influência nas atribuições e decisões 
dos demais poderes. Deste modo, os juízes e foros competentes dão preferências ao parecer do legislador ordinário; em matérias de ações de inconstitucionalidade, a postura adotada torna-se rígida e inflexível; e a abstenção na interferência da execução e conformação das políticas públicas é mais frequente.

A partir das diferenças conceituais apresentadas, observa-se que a omissão e a crise de legitimidade do sistema legislativo diante da opinião pública têm favorecido a consolidação de um ambiente institucional favorável à expansão do judiciário, no sentido de influir e direcionar as decisões que competem aos demais poderes. $\mathrm{O}$ crescente processo de judicialização condiciona a maior participação propositiva de magistrados e foros jurídicos na defesa de interesses políticos e partidários. Desta maneira, o árbitro pode atuar politicamente de forma tanto progressista como conservadora, podendo variar de acordo com seu grau de fidelidade partidária e ideológica ou seu caráter de maior ou menor pragmatismo, colocando-o acima das querelas que movem o jogo político e encerrando-se em projetos políticos individuais.

Em relação ao sistema democrático, os processos de judicialização e ativismo são acentuados pela percepção da opinião pública de um poder legislativo inoperante, fortalecendo um processo crescente (e histórico) de ilegitimidade e desconfiança em suas práticas constitucionais. A descrença da sociedade - diante de um poder público que se mostra incapaz de atender aos clamores e necessidades da população - promove maior abertura para a reivindicação de seus interesses no sistema judicial, fortalecendo a projeção das atividades dos magistrados para outras esferas e reforçando a atuação politicamente orientada dos juízes.

Reforça essa questão o fato de o Poder Legislativo ter se mostrado inoperante e sua legitimidade ter sido contestada, posto que tivesse parcela de participação no impeachment do ex-presidente Fernando Collor e criou 57 emendas à Constituição até o ano de 2009, ao invés de votar a reforma e a adequação de alguns termos da Carta Magna, fora o fato de que inúmeras Comissões Parlamentares de Inquérito (CPI $\left.{ }^{\mathrm{ee}} \mathrm{s}\right)$ foram instaladas para verificar casos de corrupção e outros desvios de conduta desde a retomada da democracia e a produção de proposições parlamentares apresentadas em cada legislatura ser pouco expressiva. Influi diretamente na questão da judicialização da política a complexa organização do modelo capitalista, visto que, se por um lado demanda-se a invasão da economia pela política com o intuito de se reproduzir o próprio sistema capitalista, o Direito adentra o espaço da política para forçar a promoção de soluções às lacunas gestadas pelos legisladores, que criam leis por vezes dúbias e vagas. (FREITAS, 2011, p. 34). 
Se a judicialização da política pressupõe a existência de uma sociedade democrática (TATE, 1994), as nações sob a égide desse regime são indissociáveis da economia capitalista, cuja natureza é intrínseca aos preceitos dos direitos civis. A própria lógica capitalista demanda a judicialização da vida social, e consequentemente da mediação dos conflitos de interesses diversos e constantemente contraditórios na sociedade brasileira. Por conseguinte, é no pluralismo das sociedades contemporâneas e da crise global nos poderes legislativos que se intensificam os processos que retroalimentam o fenômeno da judicialização da política e do ativismo judiciário.

O ativismo judicial apresenta assim dois aspectos dessemelhantes entre si: um de caráter positivo, pois aquela instância pode canalizar demandas e representar interesses de grupos não contemplados pelo Parlamento representativo; e outra essencialmente negativa, já que a proatividade judicial representa os problemas e debilidades do Congresso Nacional. Historicamente, a apropriação do poder privado diante da dimensão coletiva do Estado e seus reflexos no sistema de justiça é um traço constante na formação e desenvolvimento da sociedade brasileira. Com isso, figuras como o "juiz nosso" podem colocar em risco a formação de uma cultura política pautada na igualdade jurídica entre os cidadãos, essencial para o aprofundamento da experiência e da qualidade da democracia brasileira. Contudo, há de ressaltar que não há consenso na literatura especializada quanto aos eventuais ganhos ou prejuízos do processo de judicialização e ativismo judicial em termos de cultura política democrática.

\section{O Sentido da judicialização no Brasil}

O processo de judicialização da vida ordinária, enquanto pressupostos da conformação institucional dos estados nacionais modernos, envolve uma transferência de poder para juízes e tribunais especializados no campo legislativo, contribuindo com alterações significativas nas relações sociais e na experiência democrática de participação política. Nas sociedades contemporâneas pautadas pela ideia de direitos, o fenômeno tem múltiplas causas e representa uma tendência mundial. Em relação à sociedade brasileira esta dinâmica tem suas origens com o processo de redemocratização do país após o fim do regime militar, tendo sua expressão máxima na promulgação da Constituição Federal de 1988.

Ao expandir e fortalecer o Poder Judiciário, a Carta Magna brasileira operou transformações no sistema de justiça. A partir dela o Judiciário deixou de ser um departamento técnico-especializado a serviço de um governo discricionário, estruturado na 
assimetria entre os poderes constituintes do Estado nacional. Desse modo, tornou-se um poder político capaz de fazer valer a Constituição Federal e as leis, seja através da revisão constitucional das decisões em outras esferas decisórias ou através do conflito e por vezes sobreposição aos demais poderes.

O contexto de expansão do campo de atuação das instituições judiciais brasileiras, em conformidade com os processos de judicialização da vida ordinária nas sociedades contemporâneas é também expresso no surgimento do Ministério Público Federal e suas circunscrições regionais. Partindo do pressuposto da hipossuficiência da sociedade em defender e fazer valer os seus interesses, a relevância daquela atuação para além do aspecto estritamente penal - e a sua presença crescente nas defensorias públicas - carrega os elementos constitutivos da nova conformação jurídica e política desta instituição.

A respeito dos processos que buscam de modo crescente normatizar e jurisdificar as condutas individuais e coletivas dos indivíduos, Barroso atribui ao ordenamento institucional brasileiro elemento-chave para a compreensão da reverberação desse processo no Brasil.

[...] a constitucionalização abrangente, que trouxe para a Constituição inúmeras matérias que antes eram deixadas para o processo político majoritário e para a legislação ordinária. Essa foi, igualmente, uma tendência mundial, iniciada com as Constituições de Portugal (1976) e Espanha (1978), que foi potencializada entre nós com a Constituição de 1988. A Carta brasileira é analítica, ambiciosa, desconfiada do legislador. (BARROSO, 2012, p. 23).

Em essência, constitucionalizar uma ação política com base na estrutura jurídica representa a transformação da política em matéria do Direito. Se uma temática referente a um preceito constitucionalmente assegurado (seja individual ou coletivo) é consubstanciada em termos normativos, ela se transforma, potencialmente, em uma pretensão jurídica, podendo assim ser formulada sob a forma de ação judicial e implicar propositivamente nos processos decisórios dos demais agentes políticos.

Ainda, um terceiro elemento presente na análise do surgimento do processo de judicialização no ambiente político-institucional brasileiro refere-se ao sistema de controle de constitucionalidade, dotado de ampla abrangência em seu campo de atuação. Em referência aos mecanismos que possibilitam a expansão das atividades do judiciário, diz ele:

Referido como híbrido ou eclético, ele combina aspectos de dois sistemas diversos: o americano e o europeu. Assim, desde o início da República, adota-se entre nós a fórmula americana de controle incidental e difuso, pelo qual qualquer juiz ou tribunal pode deixar de aplicar uma lei, em um caso 
concreto que lhe tenha sido submetido, caso a considere inconstitucional. Por outro lado, trouxemos do modelo europeu o controle por ação direta, que permite que determinadas matérias sejam levadas em tese e imediatamente ao Supremo Tribunal Federal. A tudo isso se soma o direito de propositura amplo, previsto no art. 103, pelo qual inúmeros órgãos, bem como entidades públicas e privadas - as sociedades de classe de âmbito nacional e as confederações sindicais - podem ajuizar ações diretas. Nesse cenário, quase qualquer questão política ou moralmente relevante pode ser alçada ao STF. (BARROSO, 2012, p. 24).

A despeito da intensificação do processo de judicialização ter início com a promulgação da $\mathrm{CF} / 88$, a partir de uma perspectiva histórica denota-se que o processo no qual as cortes supremas foram convocadas a processar juridicamente matérias de natureza política não se apresentam como novas tendências nas relações com os poderes legislativos e executivos. Nos últimos aos o Supremo Tribunal Federal (STF) adquiriu acentuada relevância na discussão de temas referentes à organização da sociedade brasileira, desde assuntos como a demarcação de terras indígenas e a regulamentação fundiária da terra até a reforma e organização da administração pública. Determinou os limites da atuação das Comissões Parlamentares de Inquérito (CPI), discutiu a atuação do Ministério Público e obteve protagonismo na discussão das reformas previdenciárias propostas na gestão FHC (19952003) e Lula (2003-2011).

Todavia, deve-se destacar que a estruturação do sistema judicial brasileiro com a redemocratização obriga as supremas cortes, especificamente o STF, a se posicionar diante do debate público quando acionado. O seu papel de mediador dos conflitos sociais e política é resultado de sua natureza institucional, porém é no processamento desses conflitos que se pode observar a militância judicial por parte dos magistrados, assim como na intencionalidade da utilização da via processual para a resolução das disputas político ideológicas.

Como anteriormente mencionado, a adoção de um Tribunal Constitucional enquanto mecanismo de controle dos demais poderes implicou alterações nos padrões para a organização de políticas públicas. Esse mecanismo não só viabilizou a participação do Judiciário nos processos decisórios como também o colocou em uma situação estratégica diante dos outros poderes. O movimento da judicialização (e até mesmo do ativismo jurídico) no Brasil opera sob a forma dos mecanismos de propositura das Ações Diretas de Inconstitucionalidade (ADINs), Arguições de Descumprimento de Preceito Fundamental (ADPFs) e Ação Declaratória de Constitucionalidade (ADC) ferramentas processuais surgidas com a promulgação da Constituição de 1988. 
Conforme o autor, o STF tem tido participação importante na formulação do discurso político nacional e no dimensionamento da ordem política. De acordo com os estudos explanados em outro momento, os estudos nacionais sobre a judicialização da política e o ativismo judicial adquiriram as características nacionais, oriundas da sociedade brasileira, da organização político-institucional, do modelo econômicos e estratégicos.

Dada a natureza das matérias julgadas pelo STF, evidencia-se que essas possuem reflexos diretos na Nação e muitas das matérias tramitadas envolvem questões de cunho político. Apesar da ausência de iniciativa popular, dado as limitações impostas para a impetração de ADINs, ADPFs e ADC, as decisões tem influências diretas no cotidiano da sociedade brasileira, individualmente e nas ações em coletivo, sedo os julgamentos proferidos pelo STF acatados em sua maioria, em consequência de sua posição de "guardião da Constituição".

Nas ações de controle institucional, de acordo com a definição da própria corte, buscando normatiza suas análises em preceitos imparciais e com isso isentos, desconsiderando os processos de judicialização e ativismo judicial aqui analisados, ela "se dá em processos objetivos - ou seja, não se discutem casos concretos, e sim a lei em tese. O entendimento adotado tem efeito vinculante e eficácia erga omnes (para todos).” (BRASIL,. 2014)

$\mathrm{Na}$ conformação do corpo decisório deste tribunal, diferentemente da suprema Corte estadunidense, onde os magistrados são eleitos pelo voto popular, no Brasil os Ministros do Supremo são indicados pela presidência da República a partir de lista tríplice outorgada pelo Senado Federal. Devem possuir notável saber jurídico e reputação impoluta, e podem permanecer por um período de vinte a trinta anos no cargo. Em relação ao trâmite das matérias em julgamento, a página oficial do órgão na internet explica que:

Os atos processuais do magistrado podem ser divididos em dois grupos: despachos e decisões. Nos Tribunais as decisões devem, em regra, ser proferidas de forma colegiada. Os Ministros, no entanto, podem, em hipóteses determinadas, proferir decisões de forma monocrática, ou seja, sem levar ao órgão colegiado. As decisões colegiadas dos Tribunais são denominadas acórdãos. O julgamento é o ato de decidir o processo e o acórdão é o documento escrito, composto pelo relatório e pelos votos de todos os Ministros que tenham participado do julgamento, que é efetivamente juntado ao processo. (BRASIL, 2014).

Buscando dimensionar em termos quantitativos o desempenho do STF no controle das ações dos demais poderes, no ano de 2014 o Plenário do Supremo Tribunal Federal julgou 
181 ações de controle institucional, em relação à constitucionalidade das ações deliberadas nos diversos níveis federativos, tanto a âmbitos locais como nacional. Em relação ao ano anterior, houve um aumento em mais de três vezes no número de ações de constitucionalidade impetradas. O colegiado proferiu decisões em 166 ações diretas de inconstitucionalidade (ADIs), 14 arguições de descumprimento de preceito fundamental (ADPFs) e uma ação declaratória de constitucionalidade (ADC).

Tomando como base as Ações Diretas de Inconstitucionalidade (ADINs), podemos constatar que, das 5.666 ADINs impetradas de 1988 até 2017, grande parte foram requeridas por confederações sindicais ou entidades de classe. As ADINs também se tornaram instrumentos de contestação política quando partidos políticos a utilizam frequentemente para frear ou inviabilizar alterações em curso. Em estudo realizado no ano de 2006, Veridiana Alimonti traça uma relação entre a utilização do mecanismo de controle concentrado e os impetrantes das ações (Tabela 1).

Tabela 1: Tipo de requerente - Número de ações \%

\begin{tabular}{|l|c|c|}
\hline Partidos Políticos & 28 & 62,2 \\
\hline Associação de trabalhadores & 6 & 13,3 \\
\hline Governadores & 5 & 11,1 \\
\hline OAB & 3 & 6,6 \\
\hline Assembleias Legislativas & 3 & 6,6 \\
\hline TOTAL & 45 & 100 \\
\hline
\end{tabular}

Fonte: Alimonti (2006)

Apesar do contexto em que os conflitos judiciais travados durante o período 19892002 tenham tido como pano de fundo um embate político-ideológico envolvendo a defesa de duas concepções diferentes de Estado, em uma conjuntura de liberalização e grandes transformações na estrutura econômica brasileira, nota-se a predominância da utilização dessas ferramentas enquanto mediadora do conflito político-partidário (Tabela 2) na esfera judicial, sobretudo na Suprema Corte.

Fonte: Alimonti (2006)

Tabela 2: Partidos - $\mathrm{N}^{\circ}$ de ações

\begin{tabular}{|l|c|}
\hline PT & 14 \\
\hline PDT & 11 \\
\hline PSB & 6 \\
\hline PC do B & 3 \\
\hline TOTAL & 28 \\
\hline
\end{tabular}

Em decorrência da grande presença de partidos politicamente orientados à esquerda a frente dos pedidos de revisão constitucional, nota-se a presença de aspectos ideológicos na 
extensão ao âmbito judiciário das disputas realizadas nos demais poderes. A consideração realizada busca denotar as posições ideológicas presentes na utilização destes recursos, assim como o papel e influência outrora exercido pelas agremiações partidárias no processo de judicialização da política, fenômeno crescente até os dias atuais.

Além do mais, a crescente demanda por direitos sociais, civis e políticos por parte de uma sociedade cada vez mais ativa e participante na reivindicação de seus direitos acentua e dimensiona o processo de participação dos partidos de esquerda na judicialização de matérias políticas e ativismo judicial. A relação tem como fundamento o caráter ideológico desses partidos, associados (ao menos nas diretrizes de suas agendas) a defesa de direitos historicamente adquiridos ou ligados às concepções democráticas que defendem historicamente os marginalizados do processo político.

A partir desse pressuposto, caberia ainda a discussão se as deliberações proferidas pelo STF e o processo de formulação de sua agenda vem adquirindo caráter elitista ou então postura mais vigorosa em defesa dos preceitos fundamentais que norteiam o Estado democrático de direito e os princípios estruturantes da Constituição de 1988. Pois, se ao menos na formulação as ADIs estão revestidas de princípios democráticos, existe forte vinculação de algumas questões com grupos de interesses ou até mesmo o privilégio de assuntos econômicos e fiscais na formulação da agenda da suprema corte federal.

\section{Considerações finais}

Em decorrência da consolidação dos regimes democráticos (ao menos no mundo ocidental) na conformação política dos estados nacionais modernos, fundados na égide da economia capitalista e no princípio de divisão dos poderes da República, o fenômeno do protagonismo do judiciário sob os demais poderes constitui-se enquanto fenômeno global.

Com as transformações ocorridas na própria noção de direitos e sua elevação a categoria central no dimensionamento e estruturação das sociedades modernas, a sociedade civil passa a exigir de seus respectivos governantes crescentes respostas aos problemas por elas enfrentados, assim como formulações que nortearam suas escolhas e ações futuras.

A despeito das diferenças institucionais existentes entre as diversas nações, sobretudo aquelas com posições privilegiadas no sistema internacional de poderes, o processo de protagonismo das instâncias judiciais diante de questões e disputas partidárias torna-se fenômeno recorrente e indissociável do processo democrático. Como apresentado, é no delineamento institucional do Estado que a atribuição de revisão constitucional proporciona a 
estes órgãos seu potencial para uso político, conformando e acentuado o processo de judicialização da política.

Concomitantemente, a primazia de grupos de pressões ligados a interesses financeiros sob a prática política independente reforça a influência e atuação desses grupos sob os membros magistrados das supremas cortes institucionais, fortalecendo sobremaneira o fenômeno do ativismo jurídico por parte de seus membros representantes. Por outro lado, a partidarização e politização dos árbitros constitucionais podem promover e orientar as ações desses agentes no sentido de assegurar os direitos de grupos socialmente fragilizados, fazendo valer as diretrizes cidadãs da Lei maior nacional, proporcionando o aprofundamento da experiência democrática.

Em relação ao caso brasileiro, em virtude de suas especificidades, o processo de canalização dos interesses de grupos sociais mais vulneráveis ocorre através da atuação dos partidos políticos. As evidências aqui apresentadas apontam para maior protagonismo dos partidos identificados à esquerda na defesa e promoção dos valores e mecanismos institucionais que visam favorecer os grupos não priorizados na atuação governamental. Além do mais, a conformação jurídica brasileira dificulta a utilização dos mecanismos de controle de constitucionalidade criados na Constituição Federal por parte da sociedade civil na defesa de seus interesses, assim como reforça a influência do capital político na estruturação dos tribunais superiores, devido à nomeação dos magistrados constituir-se da indicação pelo Executivo e ratificação pelo Legislativo.

A partir de uma leitura atual sobre os diversos acontecimentos políticos no Brasil, constantemente marcado por escândalos de corrupção sistêmica e descasos com a gestão pública, o descrédito da opinião pública diante da classe política acirra ainda mais um quadro de ilegitimidade e descrédito da atividade política. Relacionado a perca de autonomia do Estado-nação, em face de sua apropriação pelo poder privado, diminui acentuadamente sua capacidade em fornecer respostas satisfatórias às crescentes demandas societárias, acirrando o descrédito estatal e a corrosão de suas bases de atuação legítima.

Posto isto, torna-se evidente que o processo de utilização do poder judiciário enquanto instrumento de disputas políticas e mediador dos conflitos, assim como seu redimensionamento enquanto agente político (já favorecido por seu papel de "guardião" constitucional) intensifica o processo de judicialização da política. Por outro lado, a crescente demanda e pressão exercida sob os magistrados por diversos setores exigem cada vez mais a atuação "partidarizada" desses agentes, principalmente após a centralidade que suas ações obtiveram nos rumos dos grandes acontecimentos que marcam o noticiário político atual. 
Portanto, o sentido do ativismo promovido pelos magistrados brasileiros no atual momento da vida pública nacional - e o seu elevado poder de influir nos desígnios da nação pode colocar em risco o aprofundamento da experiência democrática brasileira, essencial para a consolidação de uma ordem social mais justa, solidária e cidadã.

\section{REFERÊNCIAS}

ALIMONTI, Veridiana. O controle de constitucionalidade das privatizações: o contexto político e o tempo nos votos do Supremo Tribunal Federal. Monografia apresentada para conclusão do curso da Escola de Formação, Sociedade Brasileira de Direito Público, 2006.

BARROSO, Luis Roberto. Judicialização da Vida. Judicialização, ativismo judicial e legitimidade democrática. Revista Esythesis, v. 5, n. 1, 2012.

CARVALHO, Ernani Radalgues. O sentido do processo de judicialização no Brasil: Em busca da judicialização da política no Brasil. Apontamento para uma nova abordagem. Revista Sociologia Política, Curitiba, v. 23, 2014.

DEBORA, A; KOERNER, Andrei. Judicialização e democracia: Sentido da judicialização da política: duas análises. Revista Lua nova, 2013.

FREITAS, Paulinny Marques. Diferenciação entre judicialização e ativismo judicial. Judicialização na política: uma análise das ações diretas de constitucionalidade a partir do Estado de Goiás. Dissertação apresentada como requisito para obtenção do título de Mestre em Ciência Política, Universidade Federal de Goiás, Goiás, 2014.

NAPOLITANO, Carlo José. A judicialização da política nos tribunais federais: análise de julgamentos relacionados à reforma de Estado dos anos 90. Tese de Doutorado.

Universidade Estadual Paulista. Araraquara, 2008.

BRASIL. Supremo Tribunal Federal. STF registra aumento de $351 \%$ no número de ADI, ADC e ADPF julgadas em 2014. Disponível em:

<http://www.stf.jus.br/portal/cms/verNoticiaDetalhe.asp? idConteudo=283422>. Acesso em: 07 jul. 2017.

VIANA, Oliveira. Instituições Políticas Brasileiras. Brasília: Senado Feral, Secretaria Especial de Editoração, 1999.

\section{Como referenciar este artigo}

MACIEL, João Pedro. Sentidos e implicações do processo de judicialização da política no Brasil. Rev. Sem Aspas, Araraquara, v. 6, n. 2, p. 94-109, jul./dez., 2017. E-ISSN: 23584238 . 